\title{
Changes and recovery of soil bacterial communities influenced by biological soil disinfestation as compared with chloropicrin-treatment
}

\author{
Subrata Mowlick', Takashi Inoue ${ }^{2}$, Toshiaki Takehara ${ }^{3}$, Nobuo Kaku', Katsuji Ueki ${ }^{1}$ and Atsuko Ueki ${ }^{1 *}$
}

\begin{abstract}
Soil bacterial composition, as influenced by biological soil disinfestation (BSD) associated with biomass incorporation was investigated to observe the effects of the treatment on the changes and recovery of the microbial community in a commercial greenhouse setting. Chloropicrin (CP) was also used for soil disinfestation to compare with the effects of BSD. The fusarium wilt disease incidence of spinach cultivated in the BSD- and $\mathrm{CP}$-treated plots was reduced as compared with that in the untreated control plots, showing effectiveness of both methods to suppress the disease. The clone library analyses based on 165 rRNA gene sequences showed that members of the Firmicutes became dominant in the soil bacterial community after the BSD-treatment. Clone groups related to the species in the class Clostridia, such as Clostridium saccharobutylicum, Clostridium tetanomorphum, Clostridium cylindrosporum, Oxobacter pfennigii, etc., as well as Bacillus niacini in the class Bacilli were recognized as the most dominant members in the community. For the CP-treated soil, clones affiliated with the Bacilli related to acid-tolerant or thermophilic bacteria such as Tuberibacillus calidus, Sporolactobacillus laevolacticus, Pullulanibacillus naganoensis, Alicyclobacillus pomorum, etc. were detected as the major groups. The clone library analysis for the soil samples collected after spinach cultivation revealed that most of bacterial groups present in the original soil belonging to the phyla Proteobacteria, Acidobacteria, Bacteroidetes, Gemmatimonadetes, Planctomycetes, TM7, etc. were recovered in the BSD-treated soil. For the CP-treated soil, the recovery of the bacterial groups belonging to the above phyla was also noted, but some major clone groups recognized in the original soil did not recover fully.
\end{abstract}

Keywords: Anaerobic bacteria; Biological soil disinfestation (BSD); Clone library; Chloropicrin; Clostridial group; Wilt disease of spinach

\section{Introduction}

Soil fumigation is an effective method to control soilborne plant pathogens and soil is generally fumigated with chemicals before planting high-value cash crops. Although soil-borne pests were historically managed by methyl bromide (MeBr) fumigation, it has been banned due to its detrimental effects on the stratospheric ozone layer (Prather et al. 1984; Ristaino and Thomas 1997). $\mathrm{MeBr}$ is being phased out as it is still in limited use

\footnotetext{
* Correspondence: uatsuko@tds1.tr.yamagata-u.ac.jp

${ }^{1}$ Faculty of Agriculture, Yamagata University, 1-23, Wakaba-machi, Tsuruoka 997-8555, Yamagata, Japan

Full list of author information is available at the end of the article
}

around the world. Chloropicrin (CP) as an alternative of $\mathrm{MeBr}$ has been widely used for soil fumigation in many countries of the world (Ibekwe et al. 2004; Takeuchi 2006). Since chemical fumigants are known to have broad biocidal activities in addition to pathogen control (Anderson 1993), many general soil microbes may also be affected according to their sensitivity to the chemicals. In contrast, biological soil disinfestation (BSD), mainly developed in the Netherlands (Blok et al. 2000) and Japan (Shinmura 2004) in organic agriculture, suppresses soil pathogens based on microbial activity on incorporated plant biomass under anaerobic conditions without using any chemical fumigants. BSD has attracted our interest as an environ- 
mentally friendly tool and a suitable alternative to chemical fumigation as well as other non-chemical methods for soil-borne disease management. The principles of BSD conducted in Japan include three steps: (1) incorporating plant biomass into the soil, (2) flooding the soil by irrigation, and (3) covering the soil surface with plastic films for about three weeks to induce reducing soil conditions (Shinmura 2000, 2004). The total process is completed within one month and crops can be planted after removing the plastic film and plowing the fields. Plant biomass sources such as Brassica spp., wheat bran, rice straw, rice bran, Avena spp., grasses, or other organic substances have been incorporated in BSD against soil-borne pests and diseases (Shinmura 2004; Goud et al. 2004; Momma 2008).

In our previous studies, using model experiments of BSD with wheat bran or Brassica juncea and Avena strigosa plants as biomass sources, we successfully controlled pathogen populations (Fusarium oxysporum f. sp. lycopersici, wilt pathogen of tomato and $F$. oxysporum $\mathrm{f}$. sp. spinacea, wilt pathogen of spinach) incorporated into soil (Mowlick et al. 2012a, b). We analyzed the bacterial communities in the BSD-treated soil samples by polymerase chain reaction-denaturing gradient gel electrophoresis (PCR-DGGE) and clone library analysis based on the 16S rRNA gene sequences and it was shown that the community structures changed drastically in response to the treatments. Strictly anaerobic bacteria in the phylum Firmicutes, especially of the class Clostridia, became major bacterial groups in the soil communities together with some other aerobic or facultative anaerobic bacteria from the classes including Bacilli and Gammaproteobacteria. Considering large scale crop production, it is necessary to utilize results from field experiments to increase reliability of findings from model experiments. Thus, it is important for us to prove the efficacy of BSD for controlling soil-borne disease under field conditions (in practice) and to know the changes and recovery of the bacterial community structures in soil as affected by the treatments.

Soil microbial communities play various important roles in controlling soil fertility and plant yields (Pankhurst and Lynch 1994). Especially, the functioning of aerobic communities is essential for normal growth of most of the plants by maintaining nutrient availability and other synergistic activities. However, any fumigation treatment may cause disturbance of the soil microbial ecology such as elimination, proliferation or inclusion of specific microbial groups in the soil. Alterations in the microbial community composition may lead to changes that interfere with the functional diversity and, ultimately, the overall soil quality (De Boer et al. 2003). Therefore, the recovery of the original bacterial community structure after disinfestation treatments is likely important for proper soil functioning and crop cultivation in the treated soil. However, only a few studies have reported the impact of disinfestation methods, including CP-treatment, on soil bacterial communities and their recovery during cropping (Ibekwe et al. 2001; Hoshino and Matsumoto 2007).

The objectives of this study were to analyze the bacterial community structures in field soil after BSD-treatment in a greenhouse and to confirm the results obtained by the model experiments of our previous studies (Mowlick et al. 2012a, b). Furthermore, bacterial compositions were also analyzed for the treated soils after cultivation of spinach plants to investigate the recovery of the community during cropping. Similarly, CP-treated soil in the same greenhouse was also analyzed to compare with the results of the BSD-treatment. Clone library analysis (Maidak et al. 1999) based on 16S rRNA gene sequences was mainly carried out to determine the bacterial community compositions in these soil samples.

\section{Materials and methods}

\section{Soil disinfestation and cultivation of spinach}

A field experiment was conducted in a greenhouse in Abu-cho $\left(34.3^{\circ} \mathrm{N}, 131.3^{\circ} \mathrm{E}\right)$, Yamaguchi, Japan, during June 2011. Soil was fine- textured yellow loamy soil $(\mathrm{pH}$ 5.5). Spinach had been continuously cultivated in the greenhouse for about ten years and natural infection of fusarium wilt disease (caused by Fusarium oxysporum f. sp. spinaciae) often occurred during the period. The number of treatments used in this experiment was three distributed in a randomized complete block design with three replications. The plot size for each treatment was $27.5 \mathrm{~m}^{2}$. For the control-treatment, no plant biomass or substances was incorporated into the soil. Wheat bran as BSD-treatment was incorporated at the rate of $1 \mathrm{~kg} / \mathrm{m}^{2}$ using a rotary tiller. Irrigation water was applied to both treatments $\left(100 \mathrm{~kg} / \mathrm{m}^{2}\right)$ to moisten the plots. The treated plots were covered with a double layer of plastic agricultural sheets with low gas permeability (Barrier Star film, TOKANKOUSAN Co. LTD; Sky Coat film, C.I. KASEI Co. LTD) (07 June). After three weeks of treatment (28 June), the sheets were removed and soil samples were immediately collected from the plots. Each soil sample (100 g) was obtained in triplicates from the upper $10 \mathrm{~cm}$ of soil depth and mixed well in sterile polyethylene bags. Similarly, an original field soil sample without any treatment was also collected. The soil samples collected were kept in a freezer $\left(-20^{\circ} \mathrm{C}\right)$ immediately after the sampling and preserved there until use.

For the CP-treatment, CP was applied in the field soil using an injection machine (1DQ, AGRITECNO YAZAKI Co., LTD) attached at the rear of a $5 \mathrm{hp}$ tractor (21 June). By the machine, 15-cm-deep holes (about $2 \mathrm{~cm}$ diameter) were made in every $900 \mathrm{~cm}^{2}(30 \mathrm{~cm} \times 30 \mathrm{~cm})$, and $3 \mathrm{ml}$ of 
CP (80\% solution) was injected into each hole, which was immediately filled with soil. Afterwards, the entire plot was covered with the transparent plastic sheets. The sheets were removed after a week and the plot was kept open to degas the fumigant until plowing. A soil sample was obtained on the same day (28 June) as described above.

All treated fields were plowed and spinach (cultivar Mirage) was seeded after a week (04 July). Pellet-type organic fertilizer containing fish meal (Kumiai Ube Yuki 100: N, $\left.70 \mathrm{~g} / \mathrm{kg} ; \mathrm{P}_{2} \mathrm{O}_{5}, 40 \mathrm{~g} / \mathrm{kg} ; \mathrm{K}_{2} \mathrm{O}, 10 \mathrm{~g} / \mathrm{kg}\right)(\mathrm{MC}$ FERTICOM, Co., LTD) was used as preplanting fertilizer to supply nitrogen of $20 \mathrm{~g} / \mathrm{m}^{2}$ in each soil. The application amount was determined based on the nitrogen content measured by the microdiffusion method using samples extracted from each soil with $2 \mathrm{M} \mathrm{KCl}$. Additional fertilizer was not applied throughout the cultivation. Spinach was sown using a seeding machine (Gonbe, Mukai Kogyo Inc.) with row-distance of $10 \mathrm{~cm}$ and intra-row space of $16 \mathrm{~cm}$ resulting in 63 stands $/ \mathrm{m}^{2}$. Plants were watered as needed (about 10 minutes in the morning). Weeds were pulled by hand until two weeks after seeding and insect pests were mainly controlled using insect screens (4-mm mesh size) spread at all openings of the greenhouse. Insecticides were used when the urgent need arose. After one month of cultivation of spinach, soil samples were again taken from the plots (04 August).

\section{Measurements of disease incidence and soil analysis}

Natural wilt disease incidence of spinach (caused by $F$. oxysporum f. sp. spinacea) was recorded by visual observation of total 240 plants (hill) per plot (from 12 different points for each plot) during the cropping year and fresh marketable $\left(\mathrm{g} / \mathrm{m}^{2}\right)$ yields were determined based on sampling of 40 plants from two different points in each plot. Temperature in soil (10 cm depth) covered with the sheets was monitored by data loggers during the disinfestation treatments. Air temperature inside the greenhouse was also recorded in the same way. Soil $\mathrm{pH}$ was measured in water (soil and distilled water at the ratio $1: 2.5)$ by the glass electrode method immediately after the soil sampling. The concentration of volatile fatty acids (VFAs) in soil samples was measured by gas chromatography (Hitachi G-3900) as described previously (Mowlick et al. 2012a; Ueki et al. 1986) and the concentrations are shown in the text as those determined in the supernatant of slurry samples.

\section{PCR analysis of extracted DNA from soil}

A composite sample ( $\mathrm{g}$ ) was prepared taking $1 \mathrm{~g}$ soil of each triplicate soil sample, from which $1 \mathrm{~g}$ soil was used for DNA extraction. DNA was extracted from all the soil samples using 'Ultra Clean ${ }^{\mathrm{T}}$ Soil DNA Isolation Kit'
(MO BIO Laboratories, Inc., Carlsbad, CA, USA) according to the manufacturer's instructions. Bacterial $16 \mathrm{~S}$ rRNA genes were PCR amplified using a primer set B27f (5'-AGA GTT TGA TYM TGG CTC AG-3') and U1492r (5'-GGY TAC CTT GTT ACG ACT T -3'). The composition of PCR mixture $(50 \mu \mathrm{l})$ and PCR amplification conditions were followed as described by Mowlick et al. (2012a). The PCR composition includes 1.25 U of Taq DNA polymerase, $15 \mathrm{mM}$ Tris- $\mathrm{HCl}, 50 \mathrm{mM} \mathrm{KCl}, 1.5 \mathrm{mM} \mathrm{MgCl}_{2}$, $0.1 \%$ BSA, each dNTPs at a concentration of $200 \mu \mathrm{M}$, $0.25 \mu \mathrm{M}$ of each primer, and 60-100 ng of template DNA. The PCR amplification conditions were: activation of the polymerase $\left(95^{\circ} \mathrm{C}, 12 \mathrm{~min}\right)$ followed by 30 cycles consisting of denaturation $\left(95^{\circ} \mathrm{C}, 1 \mathrm{~min}\right)$, annealing $\left(50^{\circ} \mathrm{C}, 1 \mathrm{~min}\right)$, elongation $\left(72^{\circ} \mathrm{C}, 1.5 \mathrm{~min}\right)$, and extension $\left(72^{\circ} \mathrm{C}, 2 \mathrm{~min}\right)$. Amplified DNA fragments were confirmed after agarose gel electrophoresis and staining with ethidium bromide.

\section{Preparation of clone library and sequencing}

Clone libraries were constructed to determine the bacterial community composition in the soil samples collected as described above. The names of clone libraries were designated as Pre-treatment, UTC (untreated control, or irrigated without wheat bran incorporation), UTC-Spinach (after spinach cultivation in UTC), BSD (wheat bran BSD-treatment), BSD-Spinach (after spinach cultivation in BSD-treated soil), CP, and CP-Spinach (after spinach cultivation in CP-treated soil).

The PCR products of DNA from these samples were purified using the QIAquick Gel Extraction Kit (Qiagen, Valencia, CA, and USA) and cloned into Escherichia coli JM109 competent cells following the instructions of pGEM-T Easy Vector Systems (Promega, Madison, WI, USA). The vector-harboring clones containing an insert of appropriate sizes (about $1500 \mathrm{bp}$ ) were cultured on Luria-Bertani (LB) plates by standard methods (Kaku et al. 2005). Sequence analysis (about $600 \mathrm{bp}$ ) was performed for a total of 96 clones from each soil sample using a sequence primer U515f (5' GTG YCA GCM GCC GCG GTAA-3') according to the Dye Terminator method using a capillary sequencer at Takara Co. Ltd.

\section{Database search, construction of trees and statistical analysis}

Database searches for related 16S rRNA gene sequences were conducted with the BLAST program and GenBank database (Altschul et al. 1997). The ClustalW program of DDBJ was used to align the nucleotide sequences of the clone libraries. The phylogenetic trees were made using the neighbor-joining method (Saitou and Nei 1987) with the Njplot program in the ClustalW package (Thompson et al. 1994). Construction of OTUs (operational taxonomic unit at $97 \%$ similarity level), bootstrap resampling analysis, chimera checking, and rarefaction 
analysis were carried out as described previously (Mowlick et al. 2012b). The coverage of the clone libraries $(C)$ was calculated from the equation $C=1-\left(n_{1} / N\right)$; where $n_{1}$ is the number of clones that occurred only once (frequency 1 ), and $N$ is the total number of clones examined (Good 1953). Bacterial diversity was calculated using the Simpson's index $(D)$ by the function, $D=1-\sum n(n-1) /(N(N-1))$, where $n=$ the total number of clones of a particular OTU and $N=$ the total number of clones of all OTUs. Besides, Shannon-Wiener index $\left(H^{\prime}\right)$ was determined to compare the changes in diversity of bacterial communities within the libraries by the function: $H^{\prime}=-\Sigma P_{i} \log P_{i}$, where the proportion of OTU i relative to the total number of OTU $\left(p_{i}\right)$ was calculated. All those indexes were calculated using online biodiversity calculator (http://www.alyoung.com/ labs/biodiversity_calculator.html).

\section{Nucleotide sequence accession numbers}

The nucleotide sequences obtained from the clone library analyses have been deposited in DDBJ/GenBank and assigned under the accession numbers AB734124AB734385 (261 entries).

\section{Results}

\section{Soil status and treatments effects on crop}

The mean soil temperature $(10 \mathrm{~cm}$ depth) during the soil treatments was $28.2^{\circ} \mathrm{C}$ with diurnal variations ranged from around $24.0^{\circ} \mathrm{C}$ (as the lowest in the nights) to $34.0^{\circ} \mathrm{C}$ (as the highest in the daytime). The mean air temperature in the greenhouse was $25.3^{\circ} \mathrm{C}$ with high diurnal variations (data not shown). Small amounts of VFAs, especially acetate $(6.3 \mathrm{mmol} / \mathrm{l})$ together with a trace amount of butyrate, were detected from the wheat bran-treated (BSD) soil sample collected at the end of the treatment. No VFAs were detected for other soil samples including those after cropping in the field. Soil $\mathrm{pH}$ values after treatments (UTC, BSD, and CP) were 6.2, 6.6, and 5.7, and those after cropping (UTC-Spinach, BSD-Spinach, and CP-Spinach) were 5.3, 5.6, and 5.9, respectively.

The untreated control plots showed a high incidence of spinach wilt (50.3\%) but the BSD-treatment considerably reduced disease incidence (20.1\% incidence) relative to the control (Table 1). However, the disease incidence was almost absent in the case of the CP-treated plot (0.5\%). As for the fresh marketable yields, similar amounts were

Table 1 Wilt disease incidence and yields of spinach cultivated in the treated fields

\begin{tabular}{lcc}
\hline Soil treatment & $\begin{array}{c}\text { Wilt disease } \\
\text { incidence }(\%)^{*}\end{array}$ & $\begin{array}{c}\text { Yield of spinach } \\
\left(\mathbf{g} / \mathbf{m}^{2}\right)^{*}\end{array}$ \\
\hline Untreated control & $50.3 \pm 17.2$ & $436 \pm 102$ \\
BSD & $20.1 \pm 15.7$ & $887 \pm 267$ \\
CP & $0.5 \pm 1.2$ & $767 \pm 281$ \\
\hline
\end{tabular}

* Mean \pm SD. obtained from both treatment plots $\left(887\right.$ and $767 \mathrm{~g} / \mathrm{m}^{2}$ for BSD- and CP-treated, respectively), which were much higher than the control $\left(436 \mathrm{~g} / \mathrm{m}^{2}\right)$.

\section{Changes in soil bacterial community composition by the disinfestation treatments}

Clone library analysis was conducted for the soil samples collected. The affiliations of clone sequences from each soil sample are shown in Table 2 in relation to the percentages of abundance belonging to each phylum or class of the domain Bacteria.

The pre-treatment soil showed diverse populations of different phylogenetic groups. The most abundant taxonomic group of the library was retrieved from the phylum Proteobacteria (44.0\% of the total number of clones) distributed into three classes, Alpha-, Beta-, and Gammaproteobacteria. Other dominant phylogenetic groups were affiliated with the phyla Bacteroidetes, Acidobacteria, and Gemmatimonadetes.

The UTC (untreated control) showed diversified bacterial groups like those noted in the pre-treatment soil library but with decreased percentages of clones from the classes Alpha- and Betaproteobacteria as well as the phylum Bacteroidetes. The ratio of clones belonging to the phylum Gemmatimonadetes largely increased compared with the FS library along with members in the Verrucomicrobia phylum.

For both the BSD and CP (CP-treated) clone libraries, the phylogenetic compositions changed remarkably from that of the Pre-treatment soil library. The BSD clone library showed the presence of exclusively dominant bacterial groups in the phylum Firmicutes (59.4\%, 34.8 and 24.6\% from the Bacilli and the Clostridia, respectively). Members belonging to the Acidobacteria, Bacteroidetes, Planctomycetes, and TM7 phyla disappeared and those of the phyla Proteobacteria and Gemmatimonadetes decreased as compared with the Pre-treatment soil library. For the $\mathrm{CP}$ clone library clones belonging to the class Bacilli of the phylum Firmicutes accounted for more than half $(53.6 \%)$ of the total clones. Also, a small number of clones were detected from the phyla Proteobacteria, Gemmatimonadetes, Acidobacteria, and Actinobacteria, whereas groups from other phyla were mostly absent from the library.

The relationships of clones derived from the UTC, $\mathrm{BSD}$, and CP libraries were examined in the phylogenetic tree that combined all clone groups (OTUs) from the three libraries (Figure 1). For the UTC library the clone groups related to Mesorhizobium plurifarium (the class Alphaproteobacteria), Arenimonas donghaensis (the class Gammaproteobacteria), and Gemmatimonas aurantica (the phylum Gemmatimonadetes) (90.8-97.0\% of sequence similarity for $16 \mathrm{~S}$ rRNA gene) were considered dominant members containing 4-5 clones. For the BSD 
Table 2 Composition profiles of phylogenetic groups of bacteria based on 16S rRNA gene sequences from the clone libraries

\begin{tabular}{|c|c|c|c|c|c|c|c|}
\hline \multirow[t]{2}{*}{ Phylum or class } & \multicolumn{7}{|c|}{ Clone library (\% of abundance) } \\
\hline & Pre-treatment & UTC & BSD & $\mathrm{CP}$ & UTC-spinach & BSD-spinach & CP-spinach \\
\hline Alphaproteobacteria & 26.2 & 17.7 & 11.6 & 10.7 & 30.7 & 32.9 & 25.0 \\
\hline Betaproteobacteria & 5.9 & 3.2 & 4.4 & 7.1 & 8.0 & 3.8 & 8.8 \\
\hline Gammaproteobacteria & 11.9 & 14.5 & 8.7 & - & 14.7 & 8.9 & 7.4 \\
\hline Deltaproteobacteria & - & 1.6 & 1.4 & - & 1.3 & - & - \\
\hline Acidobacteria & 10.7 & 9.7 & - & 8.3 & 9.3 & 8.9 & 4.4 \\
\hline Verrucomicrobia & - & 4.8 & - & - & - & - & 4.4 \\
\hline Bacteroidetes & 13.1 & 8.1 & - & - & 1.3 & 10.1 & 2.9 \\
\hline Planctomycetes & 3.6 & 4.8 & 2.9 & 1.2 & 4.0 & 6.3 & - \\
\hline Firmicutes (Clostridia) & - & 1.6 & 24.6 & - & - & 2.5 & - \\
\hline Firmicutes (Bacilli) & 3.6 & 3.2 & 34.8 & 53.6 & 1.3 & 3.8 & 4.4 \\
\hline Gemmatimonadetes & 8.3 & 19.4 & 7.2 & 9.5 & 14.7 & 7.6 & 14.7 \\
\hline TM7 & 5.9 & 4.8 & - & - & 2.7 & 6.3 & 8.8 \\
\hline Actinobacteria & 5.9 & 6.5 & - & 7.1 & 9.3 & 3.8 & 7.4 \\
\hline Chloroflexi & - & - & - & 2.4 & 2.7 & 3.8 & 2.9 \\
\hline Others & 4.8 & - & 4.4 & - & - & 1.3 & 8.8 \\
\hline
\end{tabular}

- , not detected.

library a clone group (OTU) related to Bacillus niacini (96.0-99.0\%) in the Bacilli, aerobic or facultatively anaerobic spore-forming groups, appeared as the largest group (23 clones), and accounted for about $85 \%$ of the clones assigned to the Bacilli in the library. Clones belonged to the Clostridia class, strictly anaerobic spore-forming groups, were obtained only in the BSD library as shown in Table 1, and many species such as Clostridium cylindrosporum (92.2\%), Clostridium saccharobutylicum (95.1\%), and Oxobacter pfennigii (95.2\%) were detected as the closest relatives of these clones.

For the CP library out of the clone groups affiliated with the Bacilli, a large number of clones were related to Tuberibacillus calidus or Sporolactobacillus laevolacticus (14 clones, 97.0-99.0\%), Pullulanibacillus naganoensis (13 clones, 99.4\%), Alicyclobacillus pomorum (4 clones, 98.0\%), and Paenibacillus spp. (7 clones, 90.0-95.2\%). Of these groups, the clones related to Paenibacillus spp. made a cluster with some clones from the BSD library, and a clone group closely related to B. niacini (5 clones, 99.0\%) was also present in the BSD library. Although the high percentages of clones affiliated in the Bacilli were found in both the BSD and CP libraries, the members retrieved from that class in the two libraries were markedly different from each other. Also, a clone group closely related to Burkholderia terricola in the Betaproteobacteria (6 clones, 97.0-99.0\%) was an almost unique dominant group (except for a clone in the BSD library) appearing in the CP library.

\section{Recovery of bacterial communities after cropping}

The bacterial population compositions in soil after spinach cultivation in all treated plots were compared with the non-treated soil (Table 2). For the UTC-Spinach (after spinach cultivation in UTC) library the ratio of clones from the phylum Proteobacteria (especially for the Alpha- and Betaproteobacteria) increased as compared with those in the UTC library. Thus the UTCSpinach library showed a similar composition profile as the Pre-treatment soil library except for the considerable decrease in the ratio of the members from the Bacteroidetes. For the BSD-Spinach (after spinach cultivation in BSD-treated soil) clone library members in the Firmicutes that dominated the BSD library declined markedly, while members of the Proteobacteria (45.6\%) especially in the Alphaproteobacteria (32.9\%) increased considerably as compared with those in the BSD library. Also, clones belonging to the Acidobacteria, Bacteroidetes, Planctomycetes, TM7, and Actinobacteria phyla reappeared in the BSD-Spinach library and the overall profile was almost the same as that of the Pre-treatment soil library except for the presence of clones from the Chloroflexi (3.8\%) and the remaining minor members $(2.5 \%)$ from the Clostridia.

For the CP-Spinach (after spinach cultivation in CPtreated soil) clone library clones of the Bacilli decreased enormously as compared with those in the CP library. Clones belonging to the phylum Proteobacteria (41.2\%) especially in the class Alphaproteobacteria (25.0\%) became dominant and the members of the class Gammaproteobac- 


\section{(a)}

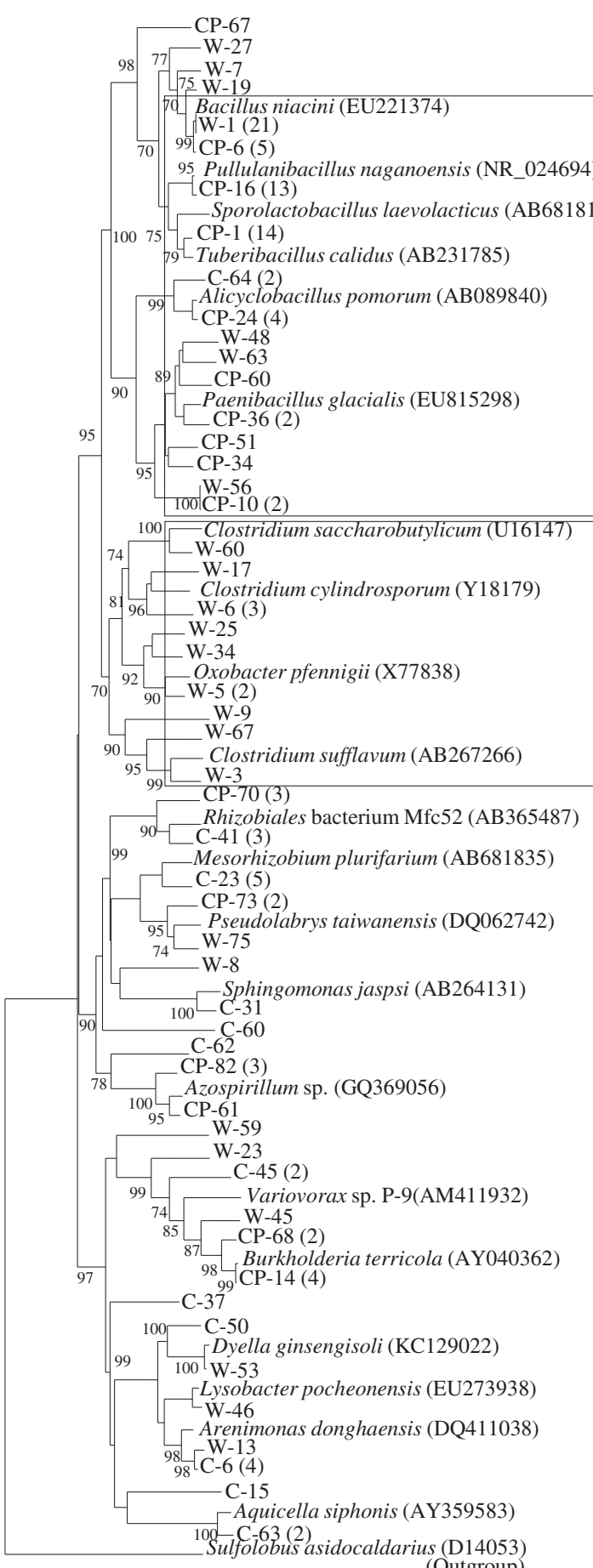

(b)




(See figure on previous page.)

Figure 1 Neighbor-joining tree showing the phylogenetic relationships of all OTUs derived from the three libraries (UTC, BSD and CP) of treated soil based on 16S rRNA gene sequences for (a) the phyla Firmicutes and Proteobacteria, and (b) other phyla (Acidobacteria, Verrucomicrobia, Bacteroidetes, Planctomycetes, Gemmatimonadetes, TM7 and others, Actinobacteria, and Chloroflexi). Designation of clone names with C, W, and CP (deposited in the DDBJ/Genbank) corresponds to the clones belonging to the UTC, BSD and CP libraries, respectively. Bootstrap values $(n=1,000)$ above $70 \%$ are indicated at branch nodes. The scale bar represents $2 \%$ estimated difference in nucleotide sequence position. The name of each clone starts with designation of the respective clone libraries. As the outgroup, Sulfolobus acidocaldarius (D14053) (the domain Archaea) 16S rRNA gene sequence was used for both cases. Accession numbers of the species are shown in the parentheses. The phylogenetic groups of phyla and class levels are shown aside the close clusters. Numbers in the parentheses aside each clone name denote the number of clones assigned to the OTU. Each clone name without parenthesis represents one OTU with one clone. The squares marked with some clone clusters show the dominancy of major groups in the communities of the respective clone libraries.

teria reappeared. Thus, it seems that a bacterial community with a similar profile to that of the Pre-treatment soil library returned in the CP-treated soil after spinach cultivation. However, clones from the Planctomycetes were absent and the ratios of the clones from both phyla Acidobacteria and Bacteroidetes were much lower as compared with those in the Pre-treatment soil library. Therefore, it appears that the community composition of the original soil did not fully recover in the spinach plot soil after the CP-treatment.

The recovery of bacterial communities after spinach cropping in the treated soil was examined by comparing the UTC-Spinach, BSD-Spinach, and CP-Spinach clone libraries with the Pre-treatment soil library in a combined phylogenetic tree (Figure 2). For most of the clone groups in the tree, clones from the four different libraries were placed in the same clusters indicating the recovery of the closely related bacterial species present in the original soil after spinach cultivation. However, some groups disappeared from the clusters consisting of the major members of the Pre-treatment soil library.

For the UTC-Spinach library, phylogenetic groups very similar to the Pre-treatment soil library were detected, although some members related to Chitinophaga arvensicola or Flavisolibacter ginsengisoli (the phylum Bacteroidetes) were not found in the library UTC-Spinach, as indicated with a low ratio of the clones in the phylum (Table 2). In the BSD-Spinach library, although two clones in the Clostridia were found, these were related to a thermophilic anaerobic bacterium, Thermincola carboxydiphila, and absent in the BSD library. Thus, typical clostridial clones found as the dominant groups in the BSD library had disappeared. The groups belonging to the phyla Proteobacteria, Acidobacteria, Bacteroidetes, Planctomycetes, Gemmatimonadetes, TM7, and Actinobacteria were present in almost all clusters consisting of clones from the Pre-treatment soil library except for a few clusters such as those related to Halomonas muralis (the class Gammaproteobacteria).

For the CP-Spinach library, the major clone groups from the Bacilli in the CP library were not found in the tree. Instead, most of the clones belonging to the phyla Proteobacteria, Gemmatimonadetes, TM7 and Actinobacteria made up the same clusters with the clones from the Pre-treatment soil library. However, clones related to Azosprillum sp. and Mesorhizobium sp. (the class Alphaproteobacteria), H. muralis (the class Gammaproteobacteria), E. modestus (the phylum Acidobacteria), F. ginsengisoli (the phylum Bacteroidetes), and Pirellula staleyi (the phylum Planctomycetes) as major groups in the Pre-treatment soil library, were only partially recovered or not recovered at all from the CP-Spinach soil sample.

\section{Bacterial diversity in soil}

The number of OTUs recognized for the clone libraries showed a varied proportion of abundance of clones and their diversity (Table 3). Rarefaction analysis based on the OTU clustering suggests that the curves for the Pretreatment soil along with other control (UTC and UTCSpinach) and spinach cultivated soil (BSD-Spinach, and CP-Spinach) were far from saturation. On the other hand, BSD and CP libraries seemed to near plateaus (Figure 3).

The estimate of diversity in the communities suggests that the original field soil harbored the most diverse communities, and all soil treatments reduced the diversity. The community diversity recovered during cropping in the treated soil.

\section{Discussion}

In the previous studies of our model experiments, BSD showed suppression of plant pathogens and anaerobic bacterial communities, while the Clostridia became dominant groups in the BSD-treated soil. In this study, we intended to confirm the BSD-effects under field conditions and compared them with a standard CP-treatment. It is always difficult to maintain desirable constant soil environments including temperature, moisture content, oxidation-reduction potential (ORP), etc., under field conditions. Controlled environment studies with smaller volumes in model experiments might enhance the production of VFAs or other products due to rapid and smooth growth of anaerobes as demonstrated in our previous studies (Mowlick et al. 2012b).

The increased soil temperature caused by covering the soil with plastic favored the rapid growth of microbes 


\section{(a)}

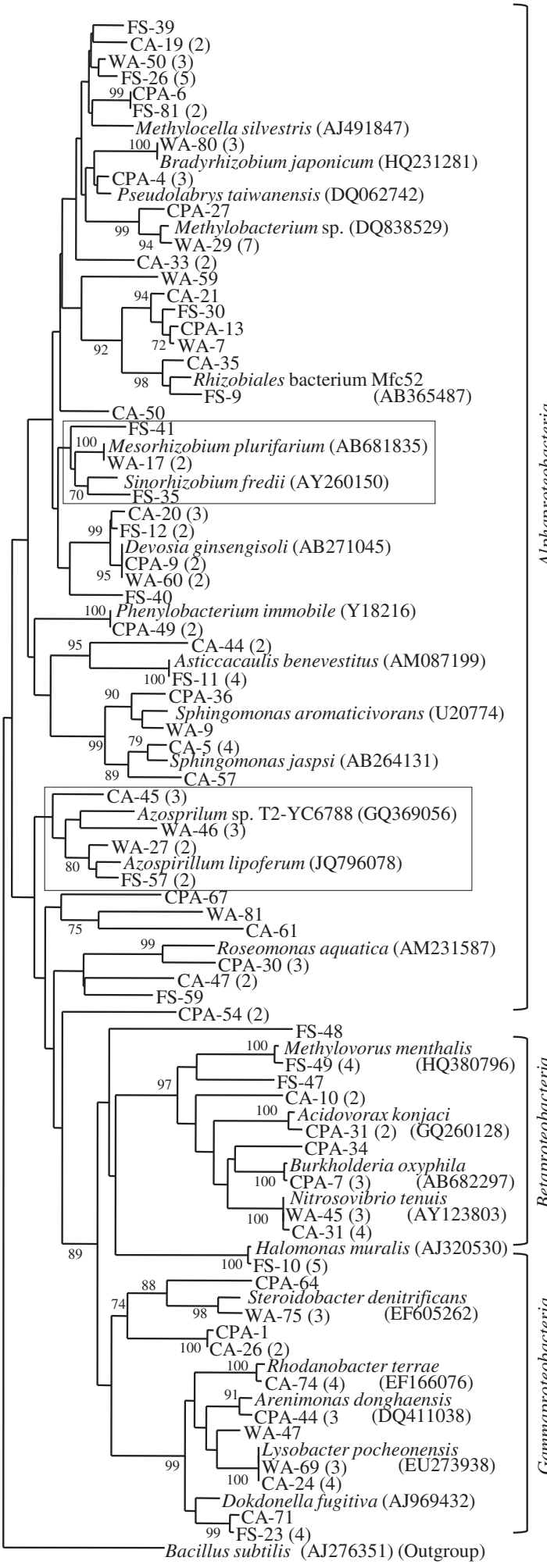

0.02

(b)

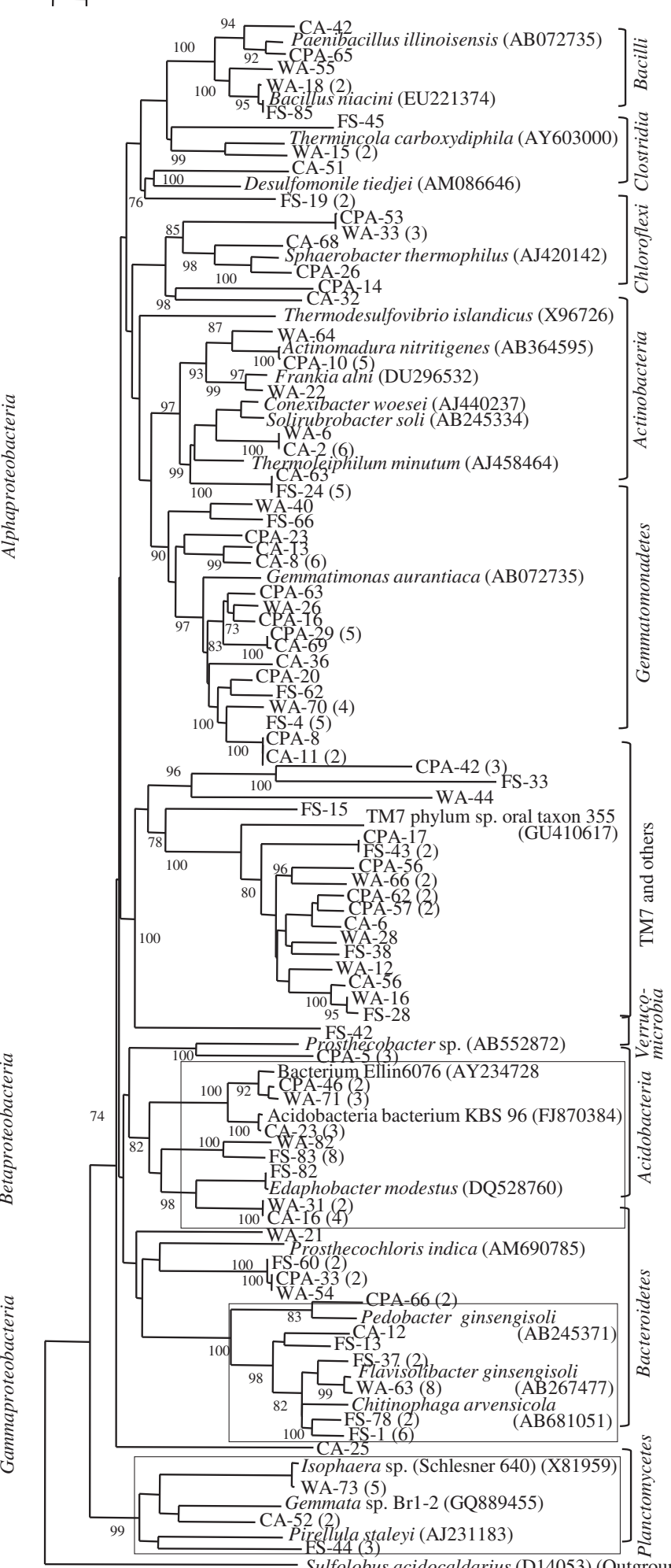

Figure 2 (See legend on next page.) 
(See figure on previous page.)

Figure 2 Neighbor-joining trees showing the phylogenetic relationships of all OTUs derived from the clone libraries Pre-treatment, UTC-Spinach, BSD-Spinach, and CP-Spinach based on 16S rRNA gene sequences for (a) the phylum Proteobacteria; (b) other phyla (Firmicutes, Acidobacteria, Verrucomicrobia, Bacteroidetes, Planctomycetes, Gemmatimonadetes, TM7 and others, Actinobacteria, and Chloroflexi). Designation of clone names with FS, CA, WA, and CPA (deposited in the DDBJ/Genbank) corresponds to the clones belonging to the Pre-treatment, UTC-Spinach, BSD-Spinach, and CP-Spinach clone libraries, respectively. The squares marked with some clone clusters show the recovery of the bacterial groups found in the original soil for the BSD-treatment but not for the CP. As the outgroups, 165 rRNA gene sequence of Bacillus subtilis DSM10 and Sulfolobus acidocaldarius (the domain Archaea) were used for (a) and (b), respectively. Tree construction and other notifications are similar as described in Figure 1.

under a low $\mathrm{O}_{2}$ concentration and the development of anaerobiosis in the successful BSD treated soil. Although we did not measure the ORP values for the treated soil in this study, the detection of many members of the Clostridia class, which require strictly anaerobic conditions for growth, in the BSD library confirmed the development of anaerobic conditions in the soil. The accumulation of VFAs such as acetate and butyrate in soil has been described as an important aspect of BSD for the suppression of soil-borne pathogens (Momma et al. 2006; Mowlick et al. 2012a, 2012b), and VFAs were also detected from the wheat bran-treated BSD soil in this study. Although their concentrations were comparatively lower than those in soil of our previous model experiments, the result indicated that VFAs did accumulate in the BSD-treated field soil in practice. Fewer numbers of spinach plants were infected in the BSD-treated field as compared with the control plots. These results confirm our previous studies where fungal pathogens were suppressed by BSD treatments and thus demonstrate the effectiveness of BSD under field conditions. $\mathrm{CP}$ has been shown to reduce fungal pathogens effectively in many vegetable crops, including tomatoes and potatoes, and can thereby increase yield (Hutchinson 2005; Sydorovych et al. 2008). The present study suggests that the BSD-treatment could decrease the crop disease incidence in the field and increase the crop yield comparable to the $\mathrm{CP}$-fumigation.

The clone library for the Pre-treatment soil contained diverse bacterial groups of different phyla and classes as identified by the analyses of non-treated soils in this and previous studies using soil from different areas in Japan. The bacterial composition in the control soil (library UTC) was similar to the profile of the Pre-treatment soil, and it was shown that the changes in the soil bacterial community caused by the control treatment (irrigation without plant biomass) were only minor. For the BSD (wheat bran)-treated soil, the increased ratios of the Clostridia and Bacilli groups in the library was consistent with the previous results of the model experiments and clearly indicated their dominance in the BSD-treated field soil. Bacterial species in the Firmicutes detected in this study usually produce spores, and thus they could survive in field soil under various conditions and proliferate in the BSD soil under the suitable growth conditions developed in the soil amended with abundant organic matter.

The detection of dominant clone groups related to the strictly anaerobic clostridial species, C. saccharobutylicum, O. pfennigii, C. cylindrosporum, C. sufflavum,etc., were also commonly found as related species in the BSDtreated soils in the model experiments, indicating their similar prevalence in the BSD-field soil. These species were believed to form various products including VFAs, alcohols or other compounds during decomposition of biomass (Krumholz and Bryant 1985; Rainey et al. 2009; Wiegel 2009), therefore suggesting the possible role of pathogenic suppression by the related species in BSDtreated soil in practice. A group closely related to $B$. niacini of the Bacilli class was the largest clone group in the BSD library. Since Bacillus species have been known to have broad functions, especially in various enzymatic activities (Wang et al. 2002; Hariprasad et al. 2011), the group is postulated to have a role in pathogen control.

Detailed analysis of bacterial communities in CP-treated soil has not been carried out except for some analyses by DGGE (Ibekwe et al. 2004; Hoshino and Matsumoto 2007). All these studies showed great changes in the bacterial communities in soil after the CP-treatment. The profile of the CP library obtained in this study suggested that some specific bacterial groups survived after the

Table 3 Estimates of bacterial diversity in the soil samples obtained after the treatments and spinach cultivation

\begin{tabular}{|c|c|c|c|c|c|c|c|}
\hline Soil sample & Pre-treatment & UTC & BSD & $\mathrm{CP}$ & UTC-spinach & BSD-spinach & CP-spinach \\
\hline Total number of clones & 85 & 66 & 68 & 80 & 75 & 79 & 67 \\
\hline Total number of OTUs & 38 & 42 & 30 & 25 & 36 & 37 & 38 \\
\hline Coverage (\%) & 76.5 & 60.6 & 73.5 & 88.7 & 76.0 & 77.2 & 70.1 \\
\hline Simpson's index & 0.97 & 0.98 & 0.89 & 0.93 & 0.97 & 0.97 & 0.98 \\
\hline Shannon-Wiener index & 4.87 & 5.19 & 4.01 & 4.10 & 4.87 & 4.87 & 5.05 \\
\hline
\end{tabular}




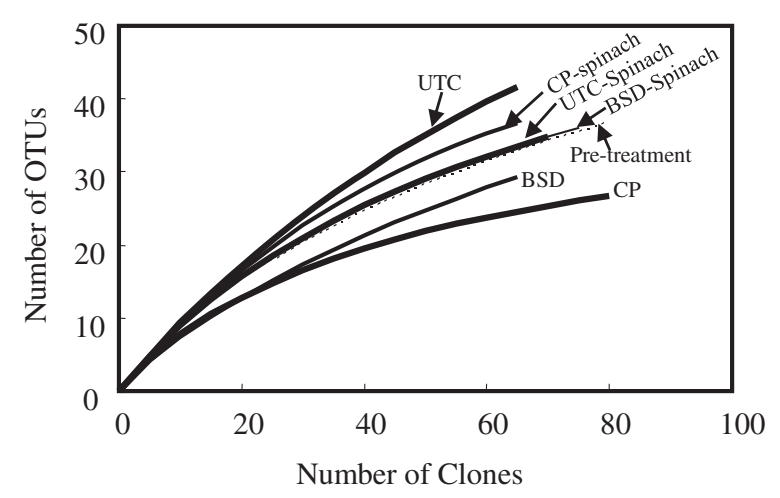

Figure 3 Rarefaction curves for the 16S rRNA gene sequences from all clone libraries. Libraries: Pre-treatment, UTC (untreated control), UTC-Spinach (after spinach cultivation in UTC), BSD (wheat bran BSD treatment), BSD-Spinach (after spinach cultivation in BSD-treated soil), CP, and CP-Spinach (after spinach cultivation in CP-treated soil).

treatment that was not detected in the BSD-treated soil. Some species in the Bacilli have been recognized to survive chemical fumigation (Ibekwe et al. 2001) and related bacterial groups were detected as major and dominant groups in the CP library of this study. These major bacterial groups might have special physiological characteristics to survive in soil under the chemical treatment. Species closely related to the dominant clone groups such as T. calidus and $P$. naganoensisas thermophilic bacteria (Hatayama et al. 2006), Sporolactobacillus sp. and P. illinoisensis as acid-tolerant and spore-forming lactic acid producing bacteria (Hyronimus et al. 2000; Bayane et al. 2010), A. pomorum as thermo-acidophilic endosporeforming bacterium (Goto et al. 2003), and B. oxyphila as an acid tolerant bacterium (Otsuka et al. 2011) are rather uncommon as soil bacteria. These species are all acidtolerant, acidophilic, or thermophilic bacteria as shown above, and thus the bacterial groups related to these species might have the specific ability to survive in the extreme environments created by the CP-treatment.

It may be possible that most of the bacterial cells present in the original field soil were killed by the CPtreatment together with pathogenic microbes, and the bacterial groups survived in the extreme condition were detected in the clone library CP. It seems invalid at present to conclude their prevalence in soil after the CPtreatment, since we did not quantify the number of bacteria in the soil samples.

The original field soil showed the most diversified population, while BSD- or CP-treatment reduced the diversity possibly due to the proliferation, elimination or dormancy of some restricted bacterial groups. However, bacterial communities had almost recovered to the original field condition after cultivation of spinach in the control and BSD-treated soils but not the CP-treated soil. As the BSD-treated soil was exposed to aerobic conditions by removing the covering sheets and plowing well in preparation for crop cultivation, the diverse aerobic bacteria might start to grow again. Also, the recovered bacterial groups might have special physiology to become re-activated in nature even after the treatment. For example, $P$. taiwanensis, designated as an aerobic bacterium closely related to the Bradyrhizobium, Mesorhizobium, and Methylobacteriumspecies (the class Alphaproteobacteria) and closely related to major clone groups in the Pretreatment soil library, might have universal distribution in soil and be able to survive the extreme treatment conditions (Kämpfer et al. 2006) and be able to recover after the treatment. Furthermore, the Bacteroidetes groups especially those related to the Flavisolibacter and Chitinophaga species are widely distributed in aerobic and anaerobic environments (Reichenbach and Dworkin 1991) and therefore could survive in BSD and recover again during crop cultivation.

Bacteria belonging to the phylum Gemmatimonadetes are frequently detected in environmental samples but $G$. aurantiaca was the only representative species isolated and characterized (DeBruyn et al. 2011). Candidate phylum TM7 is a phylogenetically independent phylum level lineage in the domain Bacteria that is widespread in the environment (Hugenholtz et al. 2001). These bacterial groups were detected in most of the clone libraries in this study and could easily recover in soil after spinach was cultivated in the treated soil. Anaerobic metabolic abilities are widely distributed among all major Planctomycetes lineages and carbohydrate fermentation or sulfur reduction should be possible mechanisms for growth and survival of the species in the group under the anaerobic treatment conditions (Elshahed et al. 2007). The Planctomycetes related bacterial groups recovered fully in the BSD-treated soil, whereas that was not the case in the CP-treated soil.

Stromberger et al. (2005) reported that $\mathrm{CP}$ and other chemical alternatives to $\mathrm{MeBr}$ have the potential to alter important microbial and enzymatic functions in soil. In this study, the clone library results clearly indicated that the soil bacterial community was greatly changed by the $\mathrm{CP}$-treatment and most of the closest relatives of the clones were rather different from those of the BSD-treated library. It was reported that both ammonium-oxidizing and nitrate-oxidizing bacteria were severely affected by the CP-treatment (Tanaka et al. 2003). Although the original population seemed to have almost recovered during the crop cultivation in the CP-treated field, some major members in the phyla Acidobacteria, Bacteroidetes, and Planctomycetes were not detected in the CP-Spinach clone library. All these phylogenetic groups seem to be universal and thus important, but rather vulnerable constituents in the soil microbial ecosystem. The severe changes in soil bacterial communities by the $\mathrm{CP}$-treatment may reduce 
the soil quality due to microbial imbalance. Therefore, the repeated application of $\mathrm{CP}$ as a soil fumigant may affect the sensitive microbial groups and destroy the original communities in soil permanently. Moreover, accelerated degradation is well known for single or repeated applications of chemical fumigant resulting in the rapid loss of the chemical's efficacy to control soil-borne pathogens (Gamliel and Dotan 2009). Therefore CP as a soil fumigant may have potential risks in the world agriculture.

The results obtained in this study clearly demonstrated that all the proliferated bacterial groups by the BSDtreatment, especially the members of the Firmicutes, became minor groups under the detection limit of the clone library analysis and almost all the original bacterial communities in soil were recovered during cultivation of crop. BSD is a technology dependent on the microbial activities and the treatment itself does not aggressively kill microbial communities. BSD is a natural microbial phenomena reinforced artificially. Our results suggest that in terms of impacts on soil microbial communities, BSD may be a more sustainable option for soil disinfestation than $\mathrm{CP}$ treatment. However the results based on present clone library analysis may require some additional analytical methods such as DGGE, PLFA, or pyrosequencing analysis to examine treatments effects more strongly. This should be studied as a remaining subject for confirmation of the study.

\section{Competing interests}

The authors declare that they have no competing interests.

\section{Authors' contributions}

SM carried out the molecular studies of soil bacterial communities and drafted the manuscript. TI carried out soil treatments, crop cultivation, and sampling of soil. TT participated in treatment design of BSD and carried out the technical guidance. NK conducted the technical guidance for cloning of the genes and drawing of the phylogenetic trees. KU participated in analysis of bacterial communities and contributed valuable suggestions to the study. AU supervised experimental design and revised the manuscript for submission. All authors read and approved the final manuscript.

\section{Acknowledgements}

This study was partly supported by a grant from the Ministry of Agriculture, Forestry and Fisheries of Japan (Development of mitigation and adaptation techniques to global warming in the sectors of agriculture, forestry, and fisheries). We wish to thank Ms Yoshimi Ohtaki, Dr. Braun Gordon, and Dr. Matthew Back for their advices and assistances.

\section{Author details}

${ }^{1}$ Faculty of Agriculture, Yamagata University, 1-23, Wakaba-machi, Tsuruoka 997-8555, Yamagata, Japan. ${ }^{2}$ Yamaguchi Prefectural Technology Center for Agriculture and Forestry, 753-0214, Yamaguchi, Japan. ${ }^{3}$ NARO Western Region Agricultural Research Center, 721-8514, Hiroshima, Japan.

Received: 14 August 2013 Accepted: 14 August 2013

Published: 17 August 2013

\section{References}

Altschul SF, Madden TL, Schäffer AA, Zhang J, Zhang Z, Miller W, Lipman DJ (1997) Gapped BLAST and PSI-BLAST: a new generation of protein database search programs. Nucleic Acids Res 25:3389-3402
Anderson JPE (1993) Side-effects of pesticides on carbon and nitrogen transformations in soils. Proceedings of the international symposium on environmental aspects of pesticide microbiology, Uppsala, Sweden, pp 61-67

Bayane A, Diawara B, Dubois RD, Destain J, Roblain D, Thonart P (2010) Isolation and characterization of new spore-forming lactic acid bacteria with prospects of use in food fermentations and probiotic preparations. Afr J Microbiol Res 4:1016-1025

Blok WJ, Lamers JG, Termorshuizen AJ, Bollen GJ (2000) Control of soil-borne plant pathogens by incorporating fresh organic amendments followed by tarping. Phytopathol 90:253-259

De Boer W, Verheggen P, Gunnewiek KPJA, Kowalchuk GA, van Veen JA (2003) Microbial community composition affects soil fungistasis. Appl Environ Microbiol 69:835-844

De Bruyn JM, Nixon LT, Fawaz MN, Johnson AM, Radosevich M (2011) Global biogeography and quantitative seasonal dynamics of Gemmatimonadetes in soil. Appl Environ Microbiol 77:6295-6300

Elshahed MS, Youssef NH, Luo Q, Najar FZ, Roe BA, Sisk TM, Bühring SI, Hinrichs KU, Krumholz LR (2007) Phylogenetic and metabolic diversity of Planctomycetes from anaerobic, sulfide- and sulfur-rich zodletone spring, Oklahoma. Appl Environ Microbiol 73:4707-4716

Gamliel A, Dotan ST (2009) Acceterated degradation of soil fumigants: occurrence and agricultural consequences. In: Gist U, Chet I, Gullino ML (eds) Recent developments in parameters. Biometrika 40:237-262. Mmanagement of plant diseases. Springer, Netherlands, pp 311-328

Good IJ (1953) The population frequencies of species and the estimation of population parameters. Biometrika 40:237-262

Goto K, Mochida K, Asahara M, Suzuki M, Kasai H, Yokota A (2003) Alicyclobacillus pomorum sp. nov., a novel thermo-acidophilic, endosporeforming bacterium that does not possess $\omega$-alicyclic fatty acids, and emended description of the genus Alicyclobacillus. Int J Syst Evol Microbiol 53:1537-1544

Goud JKC, Termorshuizen AJ, Blok WJ, van Bruggen AHC (2004) Long-term effect of biological soil disinfestation on Verticillium wilt. Plant Dis 88:688-694

Hariprasad P, Divakara SR, Niranjana SR (2011) Isolation and characterization of chitinolytic rhizobacteria for the management of Fusarium wilt in tomato. Crop Prot 30:1606-1612

Hatayama K, Shoun H, Ueda Y, Nakamura A (2006) Tuberibacillus calidus gen. nov. sp. nov., isolated from a compost pile and reclassification of Bacillus naganoensis Tomimura et al. 1990 as Pullulanibacillus naganoensis gen. nov., comb. nov. and Bacillus laevolacticus Andersch et al. 1994 as Sporolactobacillus laevolacticus comb. nov. Int J Syst Evol Microbiol 56:2545-2551

Hoshino YT, Matsumoto N (2007) DNA- versus RNA-based denaturing gradient gel electrophoresis profiles of a bacterial community during replenishment after soil fumigation. Soil Biol Biochem 39:434-444

Hugenholtz P, Tyson GW, Webb RI, Wagner AM, Blackall LL (2001) Investigation of candidate division TM7, a recently recognized major lineage of the domain Bacteria with no known pure-culture representatives. Appl Environ Microbiol 67:411-419

Hutchinson CM (2005) Evaluation of chloropicrin soil fumigation programs for potato production. Proc Fla State Hort Soc 118:129-131

Hyronimus B, Marrec CL, Sassi AH, Deschamps A (2000) Acid and bile tolerance of spore-forming lactic acid bacteria. Int J Food Microbiol 61:193-197

Ibekwe AM, Papiernik SK, Gan J, Yates SR, Yang CH, Crowley DE (2001) Impact of fumigants on soil microbial communities. Appl Environ Microbiol 67:3245-3257

Ibekwe AM, Papiernik SK, Yang CH (2004) Enrichment and molecular characterization of chloropicrin and metam-sodium-degrading microbial communities. Appl Microbiol Biotechnol 66:325-332

Kaku N, Ueki A, Ueki K, Watanabe K (2005) Methanogenesis as an important terminal electron accepting process in estuarine sediment at the mouth of Orikasa River. Microbes Environ 20:41-52

Kämpfer P, Young CC, Arun AB, Shen FT, Jäckel U, Mora RR, Lai W, Rekha PD (2006) Pseudolabrys taiwanensis gen. nov., sp. nov., an alphaproteobacterium isolated from soil. Int J Syst Evol Microbiol 56:2469-2472

Krumholz LR, Bryant MP (1985) Clostridium pfennigii sp. nov. uses methoxyl groups of monobenzenoids and produces butyrates. Int J Syst Bacteriol 35:454-456

Maidak BL, Cole JR, Parker CTJ, Garrity GM, Larsen N, Li B, Lilbum TG, McCaughey MJ, Olsen GJ, Overbeek R, Pramanik S, Schmidt TM, Tiedje JM, Woese CR (1999) A new version of the RDP (ribosomal database project). Nucleic Acids Res 27:171-173 
Momma N (2008) Biological soil disinfestation (BSD) of soil-borne pathogens and its possible mechanisms. JARQ 42:7-12

Momma N, Yamamoto K, Simandi P, Shishido M (2006) Role of organic acids in the mechanisms of biological soil disinfestation (BSD). J Gen Plant Pathol 72:247-252

Mowlick S, Hirota K, Takehara T, Kaku N, Ueki K, Ueki A (2012a) Development of anaerobic bacterial community consisted of diverse clostridial species during biological soil disinfestations amended with plant biomass. Soil Sci Plant Nutr 58:273-287

Mowlick S, Takehara T, Kaku N, Ueki K, Ueki A (2012b) Proliferation of diversified clostridial species during biological soil disinfestation incorporated with plant biomass under various conditions. Appl Microbiol Biotechnol. doi:10.1007/ s00253-012-4532-z

Otsuka Y, Muramatsu Y, Nakagawa Y, Matsuda M, Nakamura M, Murata H (2011) Burkholderia oxyphila sp. nov., a bacterium isolated from acidic forest soil that catabolizes (+)-catechin and its putative aromatic derivatives. Int J Syst Evol Microbiol 61:249-254

Pankhurst CE, Lynch JM (1994) The role of the soil biota in sustainable agriculture. In: Pankhurst CE, Doube BM, Gupta WSR, Grace PR (eds) Soil biota. CSIRO, East Melbourne, Victoria, Australia, pp 3-9

Prather MJ, McElroy MB, Wofsy SC (1984) Reductions in ozone at high concentrations of stratospheric halogens. Nature 312:227-231

Rainey FA, Hollen BJ, Small A (2009) Genus I. Clostridium Prazmowski 1880, 23 AL In: Whitman WB, Parte AC (eds) Bergey's manual of systematic bacteriology, vol 3. Springer, New York, pp 738-828

Reichenbach H, Dworkin M (1991) The order Cytophagales. In: Balows A, Truper HG, Dworkin M, Harder W, Schleifer KH (eds) The prokaryotes. Springer, New York, pp 356-379

Ristaino JB, Thomas W (1997) Agriculture, methyl bromide, and the ozone hole: can we fill the gaps. Plant Dis 81:954-975

Saitou N, Nei M (1987) The neighbor-joining method: a new method for reconstructing phylogenetic trees. Mol Biol Evol 4:406-425

Shinmura A (2000) Causal agent and control of root rot of welsh onion. PSJ soil-borne dis workshop report 20:133-143 (in Japanese with English Summary)

Shinmura A (2004) Principle and effect of soil sterilization method by reducing redox potential of soil. PSJ soil-borne dis workshop report 22:2-12 (in Japanese with English Summary)

Stromberger ME, Klose S, Ajwa H, Trout T, Fennimore S (2005) Microbial populations and enzyme activities in soils fumigated with methyl bromide alternatives. Soil Biol Biochem 69:1987-1999

Sydorovych O, Safley CD, Welker RM, Ferguson LM, Monks DW, Jennings K, Driver J, Louws FJ (2008) Economic evaluation of methyl bromide alternatives for the production of tomatoes in North Carolina. Hort Tech 18:705-713

Takeuchi S (2006) Efforts to develop and spread alternatives to methyl bromide in Kochi prefecture. Proc Vege Tea Sci 3:17-20 (in Japanese)

Tanaka S, Takayoshi K, Kozo I, Shinzo Y, Kazuhiro M, Katsutoshi S (2003) Properties and metabolic diversity of microbial communities in soils treated with steam sterilization compared with methyl bromide and chloropicrin fumigations. Soil Sci Plant Nutr 49:603-610

Thompson JD, Higgins DG, Gibson TJ (1994) CLUSTAL W: improving the sensitivity of progressive multiple sequence alignment through sequence weighting, position-specific gap penalties and weight matrix choice. Nucleic Acids Res 22:4673-4680

Ueki A, Matsuda K, Ohtsuki C (1986) Sulfate reduction in the anaerobic digestion of animal waste. J Gen Appl Microbiol 32:111-123

Wang SL, Shih IL, Wang CH, Tzeng GC, Chang WT, Twu YK, Ro JJ, Wang CL (2002) Purification of antifungal compounds from chitin by Bacillus subtilis. Enzyme Microb Technol 31:321-328

Wiegel I (2009) Family I. Clostridiaceae Pribram 1933, 90 AL. In: Whitman WB, Parte AC (eds) Bergey's manual of systematic bacteriology, vol 3. Springer, New York, p 737

doi:10.1186/2191-0855-3-46

Cite this article as: Mowlick et al:: Changes and recovery of soil bacterial communities influenced by biological soil disinfestation as compared with chloropicrin-treatment. AMB Express 2013 3:46.

\section{Submit your manuscript to a SpringerOpen ${ }^{\circ}$ journal and benefit from:}

- Convenient online submission

- Rigorous peer review

- Immediate publication on acceptance

- Open access: articles freely available online

- High visibility within the field

- Retaining the copyright to your article

Submit your next manuscript at $\gg$ springeropen.com 